\title{
From sensation to cognition: a perception-based training intervention for the development of relational competences in young Italian apprentices
}

\author{
Riccardo Sartori and Arianna Costantini \\ Department of Human Sciences, University of Verona, Verona, Italy
}

Competences

in young

Italian

apprentices

Received 11 March 2020

Revised 21 April 2020

Accepted 26 April 2020

\begin{abstract}
Purpose - This study aims to test the effectiveness of a training intervention based on the psychology of perception, delivered to young Italian workers and employees, with low education, hired with an apprenticeship contract and involved in a compulsory training course (duration $32 \mathrm{~h}$; the training intervention reported in the paper covers the first $8 \mathrm{~h}$ ) whose aim was to let them develop such relational competencies as communication and cooperation with others.

Design/methodology/approach - By making use of optical-geometric illusions and ambiguous figures, participants were accompanied through a training intervention with the dual purpose of undermining their naive certainties about why they see what they see and increasing their awareness of how the perceptual processes work. At the beginning of the intervention, at the end of the $32 \mathrm{~h}$ (that is, after about a month) and after about one year from the end of the course, participants were administered a questionnaire to monitor the results of the training course by measuring their "perception awareness".

Findings - "Perception awareness" increased from the beginning to the end of the course and still scored higher after one year. "Perception awareness" was positively related to communication and cooperation.

Originality/value - Although the literature is full of training courses delivered to improve communication and cooperation with others, little research has been carried out on perception-based training interventions delivered to young adults with low education hired with an apprenticeship contract for which this kind of training is compulsory.
\end{abstract}

Keywords Ambiguous figures, Perception awareness, Perception-based training intervention, Psychology of perception, Relational competences, Young apprentices with low education

Paper type Research paper

\section{Introduction}

Literature is full of papers (i.e. the one by Ammentorp $e$ al., 2007) and books (i.e. the one by Salas et al., 2001) dealing with training interventions whose aim is to let workers and employees develop such relational competencies as communication and cooperation with others (Costantini et al., 2019). However:

(C) Riccardo Sartori and Arianna Costantini. Published by Emerald Publishing Limited. This article is published under the Creative Commons Attribution (CC BY 4.0) licence. Anyone may reproduce, distribute, translate and create derivative works of this article (for both commercial and noncommercial purposes), subject to full attribution to the original publication and authors. The full terms of this licence may be seen at http://creativecommons.org/licences/by/4.0/legalcode

European Journal of Training and Development Vol. 45 No. $6 / 7,2021$ pp. $547-565$ pp. 547-565
Emerald Publishing Limited DOI 10.1108/EJTD-03-2020-0044 
EJTD

$45,6 / 7$

\section{8}

- The training interventions the literature in question deals with are mostly dedicated to such high professional profiles as nurses, physicians and teachers, that is to say, workers and employees with a degree who are notoriously motivated to develop such skills (Berkhof et al., 2011; Cunico et al., 2012; Tomietto et al., 2019).

- Those training interventions are based on the so-called managerial approach (Meredith and Mantel, 2011) that takes for granted knowledge that non-graduate workers and employees might not possess.

Nowadays, in Italy, various forms of apprenticeship contracts involve young workers and employees with low education and require apprentices to attend training interventions for the development of relational competences compulsorily. In such conditions, it is at least risky to rely on training interventions based on the managerial approach because the apprentices, obliged to take part in courses lasting a few hours a day for some weeks, are likely to lack both the motivation and the knowledge necessary to take advantage of such interventions. In these cases, it seems more sensible to turn to training interventions dealing with basic psychological processes, that is to say, with perception and "perception awareness" because of which the apprentices can directly experience those perceptual phenomena that are connected to our relational behaviour (Broadbent, 2013 [1]).

In this paper, we are going to present a training intervention for the development of such relational competencies such as communication and cooperation with others, which is based on the study of the psychology of perception (Grondin, 2016) and delivered to young Italian workers and employees with low education hired with an apprenticeship contract for which this kind of training is compulsory. In particular, the part concerning our perceptual processes delivered using optical-geometric illusions and ambiguous figures will be presented, as we want to stress the idea that knowing how our perceptual processes work helps us remind that what seems to simply happen outside us, both in the physical and in the social world, without any apparent contribution on our side, is instead not rarely codeveloped by us. Once we understand this, our relational competencies are positively affected (Broadbent, 2013).

\section{Theoretical background and research hypotheses}

From a theoretical point of view, the training intervention we are going to report in this paper is based on the principles of Gestalt psychology (Koffka, 2014; Kölher, 1970) and the theory of perception from the point of view of the observer exposed by Nobel Prize Eric Kandel in his two books The Age of Insight (2012) and Reductionism in Art and Brain Science: bridging the Two Cultures (2016). In these books, Kandel integrates concepts derived from psychoanalysis, Gestalt psychology, cognitive psychology and neuroscience, to explain how we learn to perceive things as we perceive them and so underlying the fact that the things as we perceive them are the results of processes based on learning. Also, he explores the differences in our perception of visual art as an example of the contribution we give, both cognitively and emotionally, to the perception and the construction of the world around us (Kandel, 2012, 2016).

Gestalt psychologists state that the world as we perceive it, the phenomenon, is the result of the interaction between something outside us - something belonging to the physical world, something similar to the concept of noumenon postulated by German philosopher Kant - and something inside us - something belonging to both the brain and the mind, something similar to the inner processes postulated by psychoanalysts, cognitive psychologists and neuroscientists along the XX century. Such Gestalt psychologists as 
Wolfgang Köhler - the author of the concept of insight, which is also used, with a different meaning, by psychoanalysts to explain specific sudden changes in their patients - Kurt Koffka and Max Wertheimer - of whom we want to cite the book entitled Productive Thinking (1982) derived this idea from psychophysics by Gustav Fechner (1966), who was interested in sensation, the automatic and unconscious reaction of such senses as sight, hearing, taste, smell and touch to appropriate stimulation - the so-called bottom-up processes - more than perception, the less automatic and less unconscious inner integration of information coming from the outside to give life to the objects as we perceive them - the so-called top-down processes.

Kandel in his books establishes a link between the physical and chemical processes operating in our brain and the contents belonging to our mind, suggesting that the brain is genetically ready to receive information from the outside because of the bottom-up processes involving the senses but also that our perception of the world depends on the way we have learnt to perceive it up to a particular time, that is to say, on such top-down processes related to our sensorial, relational and social experiences, our culture, expectations, needs, desires, etc. This is something reminding the psychoanalytic concept of projection. For example, considering the vision as a typical way by which we perceive the world, the way we see objects, events, things and people around us is based on both the processes happening in the brain and the experiences we have had the chance to do or not to do during our lifetime, which form the so-called mindset (Marr, 2010). In this framework, memory, even in its unconscious aspects, seems to play a crucial role not only in recognition of objects but also in the way we live those objects, whether in a positive, negative or neutral way (Mitterer et al., 2009; Wilson and Stevenson, 2003).

According to this theoretical position, which is the most acclaimed at the moment, such activities as education, training and development are considered fundamental in letting people explore the way they perceive the world and contribute to building it (Nevis, 2013; Sartori and Tacconi, 2017). This leads to new awareness (cognition). Besides, these activities stimulate more innovative productive thinking, which combines knowledge with creative/critical thinking, rather than a less original reproductive thinking, which is simply a way to refine what is already known, leading people to be more effective, open-minded and innovative in implementing complex behaviours based on the perception of others such as communicating and cooperating, both in everyday life and in the workplace (Sartori et al., 2013; Sartori et al., 2017; Sartori et al., 2018). People who are not appropriately educated on the way their perception works might think that the world and the objects in it are as they perceive them (Broadbent, 2013). This has the consequence that their reactions to events, both emotional and behavioural according to the ABC models by Skinner (1966) and Ellis (1994) [2], are generally read by them as the natural result of what really happens to them and little or no effort at all is made by them to consider their contribution to what they perceive, live, feel, suffer.

Despite the acknowledgement that the perceptual processes play a pivotal role in modulating our relational and social behaviours (Broadbent, 2013), little research has been carried out to test the effectiveness of perception-based training interventions among young workers and employees. Previous research has shown that a perception-based training intervention carried out among people doing physical exercise proved to be effective in improving their athletic performances in various conditions, including heat, hypoxia and reduced energy substrate availability (Tucker, 2009). This piece of research falls within the sphere of sports medicine, not within the training for communication and cooperation with others. To the best of our knowledge, no studies tested the effectiveness of a perception-based training intervention for the development of relational competences in young Italian apprentices. Therefore, the training intervention we are going to report in this paper was delivered to young Italian workers and employees (age 17-24) involved in a compulsory
Competences in young Italian apprentices 
training course (duration $32 \mathrm{~h}$ ) whose aim was to let them develop such relational competences as effective and satisfactory communication and cooperation. As communicating and cooperating with others are processes depending on the way we perceive people around us (Broadbent, 2013), the training intervention dedicated the first $8 \mathrm{~h}$ to the study of the psychology of perception (Grondin, 2016) and the way we contribute to building the world around us as we perceive it.

These are the research hypotheses:

H1. At the end of the perception-based training intervention participants show increased interest in and awareness of their perceptual processes;

H2. Participants' increased interest in and awareness of perceptual processes are positively related to their relational competences in communication and cooperation.

\section{Materials and methods}

Participants and procedure

In total, 63 young Italian workers and employees (age 17-24, mean 19, standard deviation 1.26 , male $77.7 \%$ ), with low education, hired with an apprenticeship contract for which this kind of training is compulsory and randomly divided into four groups of about 15 people each (14-17) were involved in a training intervention for relational competencies starting from the study of their perceptual processes (perception-based training intervention). Participants were recruited within the training courses that are compulsory for them as apprentices and were not informed about the aims of the research to avoid that results were biased. At the beginning of the course, at the end of the $32 \mathrm{~h}$ (that is, after about a month) and after about one year from the end of the course (follow-up), participants were administered an ad hoc questionnaire to monitor the results obtained with training by measuring their "perception awareness" and "interest in perception".

\section{Measures}

An ad hoc questionnaire was built to monitor the effectiveness of the perception-based training intervention. It allowed for the detection of the socio-demographic variables used to describe the participants and contained the following six questions about perception (rating scale from 1 = "not at all" to 5 = "completely"):

Q1. How interested are you in the topic of human perception?

Q2. How interested are you in knowing how you perceive the world?

Q3. How much do you think your way of perceiving the world influences your emotions?

Q4. How much do you think your way of perceiving the world influences your relationships with others?

Q5. How much do you think your way of perceiving the world influences what happens to you in life and at work?

Q6. How much do you think that changing your way of perceiving the world makes you function better in life and at work? 
To test the validity and reliability of the questionnaire, principal component analysis was carried out (Sartori and Pasini, 2007; Burro et al., 2011). Table 1 shows the results ( $N=120$, $\mathrm{KMO}=0.93$, Bartlett's test of sphericity $p<0.001$, cut-off $=0.30$ ) and reveals that the six questions can be grouped into two components, which were called respectively "perception awareness" ( $\alpha=0.81)$ and "interest in perception" $(\alpha=0.79)$.

The ad hoc questionnaire also comprised two questions, one about communication (C1) and one about cooperation (C2), as follows (rating scale from $1=$ "not at all" to $5=$ "completely"):

$C 1$. In your opinion, how well do you communicate with others?

C2. In your opinion, how able are you to cooperate with others in life and at work?

The perception-based training intervention for the development of relational competences

The first $8 \mathrm{~h}$ of a training course lasting $32 \mathrm{~h}$ were dedicated to letting participants gain experience with their perceptual processes. As already mentioned, the training course had the aim to let participants develop such relational competences as effective and satisfactory communication and cooperation with others, which are skills depending on the way we perceive people around us.

The structure of the perception-based training intervention is shown in Table 2, where it is possible to notice that the $8 \mathrm{~h}$ were divided into two macro-phases of about $4 \mathrm{~h}$ each: 1 . basic perception-based training (first $4 \mathrm{~h}$ ), 2. advanced perception-based training (last $4 \mathrm{~h}$ ). In turn, each Macro-phase was divided into two micro-phases of about $2 \mathrm{~h}$ each: 1.1 basic elements, 1.2 Iinsights, 2.1 Aambiguous figures, 2.2 paintings and literary pieces.

\section{Macro-Phase 1: Basic perception-based training}

Micro-Phase 1.1: Basic elements. Aims: The aim of the first $2 \mathrm{~h}$ of the perception-based training intervention was to let participant start reasoning on our perceptual processes and undermining their naive certainties about why we see what we see.

\begin{tabular}{lcc}
\hline & & Component \\
Questions & Perception awareness & Interest in perception \\
\hline Q3 & 0.816 & 0.167 \\
Q4 & 0.809 & 0.189 \\
Q5 & 0.793 & 0.173 \\
Q6 & 0.754 & 0.174 \\
Q2 & 0.279 & 0.907 \\
Q1 & 0.193 & 0.763 \\
Variance explained \% & 35.2 & 22.8 \\
Cronbach's alpha & 0.81 & 0.79
\end{tabular}

Competences in young Italian apprentices

551

\begin{tabular}{lll}
\hline & & \\
\hline \multirow{2}{*}{ Phases } & Macro-Phase 1 (first 4h) & Macro-Phase 2 (last 4h) \\
\hline Micro-Phase 1 & Basic perception-based training & Advanced perception-based training \\
& Micro-Phase 1.1 (about 2 h) & Micro-Phase 2.1 (about 2h) \\
Micro-Phase 2 & Basic elements & Ambiguous figures \\
& Micro-Phase 1.2 (about 2h) & Micro-Phase 2.2 (about 2h) \\
& Insights & Paintings and literary pieces \\
\hline
\end{tabular}

Table 1.

Results of the principal component analysis carried out on the six questions of perception $(N=120)$ 
EJTD

$45,6 / 7$

\section{2}

Stimuli: The starting point of the perception-based training intervention is Figure 1, which presents two parallel segments of equal length.

If we ask people to say what they see in Figure 1, they say they see two parallel segments of equal length. Perhaps, they do not precisely say so [3], but their different answers can all be assimilated to the one saying: "two parallel segments of equal length", so much so that if we ask them: "Are they two parallel segments of equal length"? the unanimous answer is "Yes, they are".

In the case of a training course, this suggestion should be given only after each participant has had the opportunity to answer the following questions: "What do you see here? How can this picture be described? Can you see anything else"? It is essential to insist that each participant describes as precisely and accurately as possible, other than exhaustively, what they see. Moreover, it is important to do so with each participant, so that no one gets the impression that the answers of the people preceding them are worth more than theirs.

The next step is to ask participants to say why they see what they see. Practically, participants are asked to explain the reason why they all agree that Figure 1 represents two parallel segments of equal length. We believe it is easy to imagine the irritation with which participants answer, as they consider the question meaningless and the answer obvious. Their answers can be synthesized as follows: "we see two parallel segments of equal length because they are two parallel segments of equal length. Full stop".

\begin{tabular}{|c|c|c|c|}
\hline \multicolumn{4}{|c|}{ Macro-phase 1: Basic perception-based training } \\
\hline \multicolumn{4}{|c|}{ Micro-phase 1.1: Basic elements } \\
\hline $\begin{array}{c}\text { Figure } \\
\text { number }\end{array}$ & Figure & Origin & Description \\
\hline Figure 1 & & $\begin{array}{c}\text { Two parallel } \\
\text { segments of equal } \\
\text { length }\end{array}$ & $\begin{array}{l}\text { This is the starting point of the } \\
\text { perception-based training } \\
\text { intervention }\end{array}$ \\
\hline Figure 2 & & $\begin{array}{l}\text { The Vertical- } \\
\text { horizontal illusion } \\
\text { (also known as } \\
\text { the Bisection } \\
\text { illusion) by } \\
\text { Johann Joseph } \\
\text { Oppel (1855), } \\
\text { created by using } \\
\text { the same } \\
\text { segments in } \\
\text { Figure } 1 \text { and } \\
\text { rotating the upper } \\
\text { segment by } 90 \\
\text { degrees }\end{array}$ & $\begin{array}{c}\text { The two segments of Figure 1, } \\
\text { which are of the same length, } \\
\text { are perceived as differently } \\
\text { long }\end{array}$ \\
\hline Figure 3 & & $\begin{array}{l}\text { The Müller-Lyer } \\
\text { illusion by } \\
\text { psychologist } \\
\text { Franz Carl } \\
\text { Müller-Lyer } \\
\text { (1889), created by } \\
\text { using the same } \\
\text { segments in } \\
\text { Figure 1 }\end{array}$ & $\begin{array}{c}\text { The two segments of Figure 1, } \\
\text { which are of the same length, } \\
\text { are perceived as differently } \\
\text { long }\end{array}$ \\
\hline
\end{tabular}

Figure 1.

The stimuli used in the Micro-Phase 1.1: basic elements 
This first part of the training intervention can appear trivial or even meaningless to participants and can arouse a sense of absurdity in them, given the simplicity of the picture shown in Figure 1. However, this part is fundamental for the success of the intervention itself and is functional to subsequent developments. Once established that participants have nothing else to add about the question of what they see in Figure 1 and why they see what they see, it is possible to move on to show them Figure 2.

Figure 2 presents the well-known vertical-horizontal illusion where two segments of the same length are perceived as differently long. In particular, the vertical segment is perceived as longer than the horizontal segment (or, vice versa, the horizontal segment is perceived as

Competences in young Italian apprentices

553

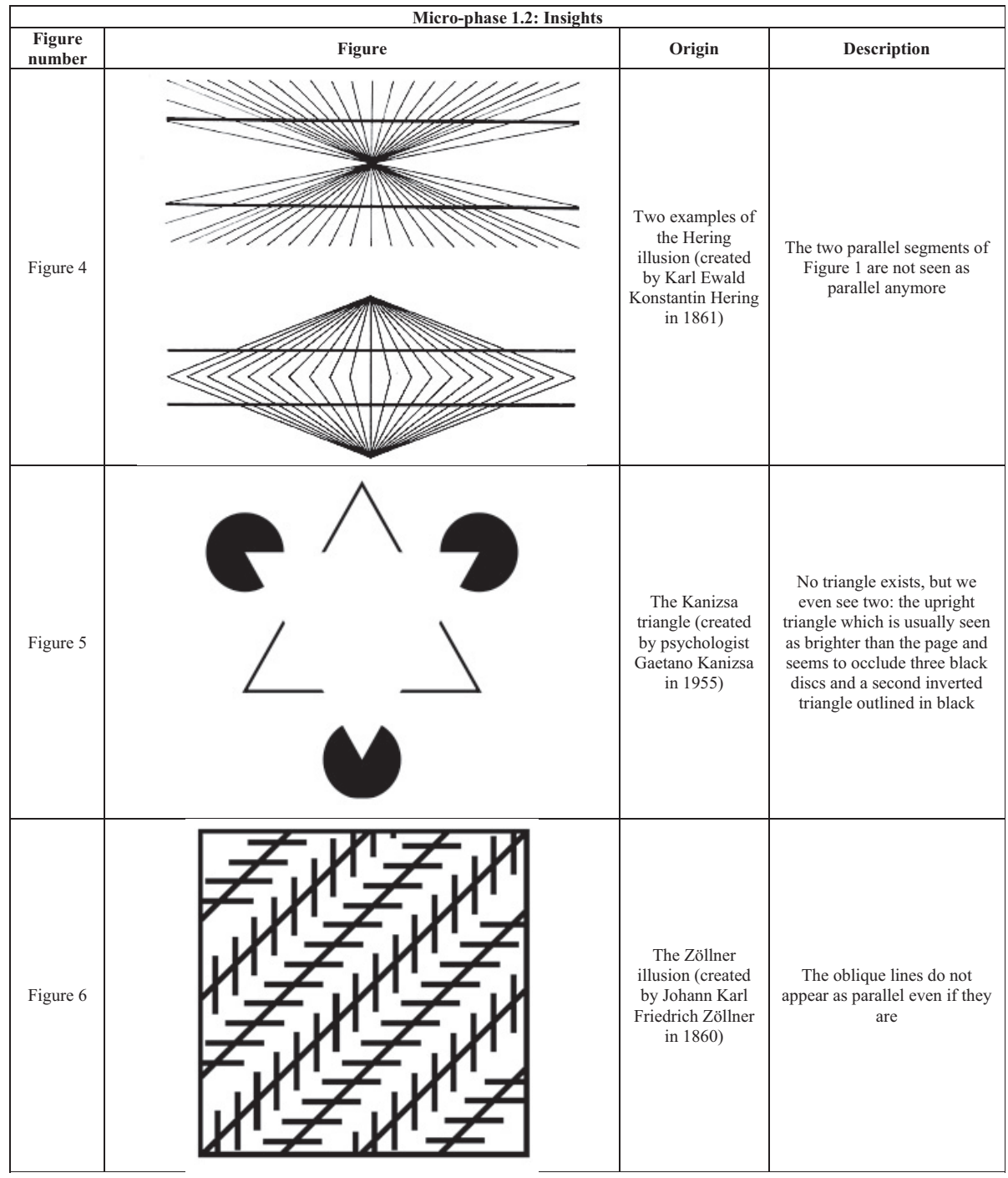

Figure 2. The stimuli used in the Micro-Phase 1.2: insights 
shorter than the vertical segment). Also, the two segments of Figure 2 are as long as the two segments of Figure 1. So, when participants are presented with this new picture, they are asked to say what they see [4] and why and their answers converge towards the one saying that:

[... .] there are two segments, one vertical and one horizontal, and the vertical segment is longer than the horizontal one (or the horizontal segment is shorter than the vertical one), and they are seen that way because they are that way,

\section{4}

They get quite surprised when they discover that the two segments of Figure 2 are actually identical to each other and also identical to those of Figure 1.

In the case of Figure 2, participants sometimes show some slight uncertainty when asked to say what they see, as if they felt they were going to be misled. However, they usually do not feel confident enough to declare with certainty that the two segments are, in fact, the same. After the "truth" has been revealed, someone happens to say something like: "I knew it! I wanted to say it!" However, they did not, which is what cares.

The discrepancy evident in Figure 2 between the physical truth of equality and the perceptual (psychological) truth of inequality between segments, discrepancy absent in Figure 1, leads to the question whether it is true or not that we see things in a certain way because they are in that way. The same two segments, which are equal in length, are seen as equal in Figure 1 and as not equal in Figure 2, based on the fact that they are parallel or perpendicular.

To stress the idea that there is a discrepancy, a gap, a mismatch between things as they physically are and things as we perceive them, and therefore, that it is not true that we see things in a certain way because they are in that way, the next step requires participants to directly give life to the famous Müller-Lyer illusion (Figure 3) starting from the segments reported in Figure 1.

The request to participants to first draw the parallel segments as equal, telling them to make sure they are equal and then to add the side elements to create the Müller-Lyer illusion before their eyes is a powerful tool with which participants experience the perceptual transformation of a piece of the world that, from a physical point of view, does not change at all. This is surprising enough to attract the attention of participants and leads them to ask questions of all kinds: "Why does this happen? What does this mean? What does it tell us about ourselves and the surrounding world"? Questions to which it is interesting, useful and effective to answer with other questions such as follows: "What do you think"? to give life to discussions and comparisons of ideas, without necessarily providing answers at this stage.

Microphase 1.2: Insights. Aims: This microphase aimed to deepen the basic elements seen in the previous micro-phase and to stress the fact that our social and relational behaviours are more easily influenced by what we perceive of the world rather than by reality in itself.

Stimuli: At this stage of the perception-based training intervention, participants could see the same two segments in three different contexts (Figures 1-3) and have experienced a change in the perception of the length of the two segments even if no change in length has occurred to them from a physical point of view.

To further proceed on the road to the crisis of the certainty according to which things are seen in a certain way because they are that way and to continue working with the parallel segments from which the perception-based training intervention started, participants are presented the pictures in Figure 4 (Figure 2), in which the two parallel segments of the starting point are not seen as parallel anymore, even if they are so from a physical point of view. In the top picture of Figure 4, the two parallel segments appear to be convex. On the contrary, in the lower picture of Figure 4, the same two parallel segments appear to be 


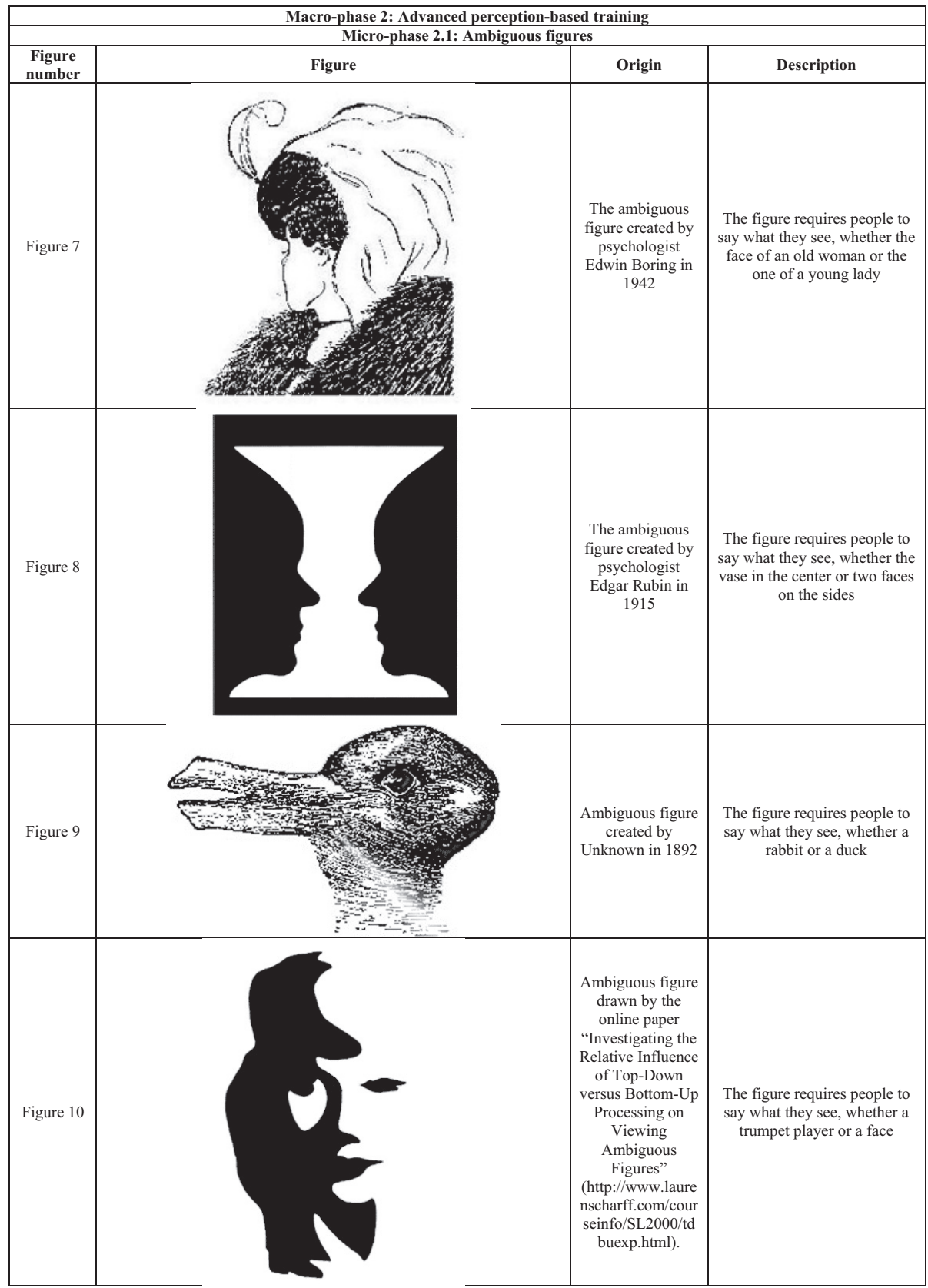

Competences in young Italian apprentices

\section{5}

Figure 3.

The stimuli used in the Micro-Phase 2.1: ambiguous figures 


\begin{tabular}{l}
$\begin{array}{l}\text { EJTD } \\
45,6 / 7\end{array}$ \\
\cline { 2 - 6 }
\end{tabular}

concave. Not only the length but also the parallelism between the two segments can be subject to changes in perception that do not correspond in the physical world.

At this stage of the perception-based training intervention, a discussion can begin to stress the evident fact that our perception of the world does not always correspond to what happens in the physical world. It is also possible to refer to the different answers that participants gave to Figures 1 and 2 (footnotes 3 and 4) as examples of how our personal experiences and visions also influence our perceptions. It is important for the subsequent topics covered in the course (communication and cooperation with others) to stress the fact that our behaviour is influenced by what we perceive more than what the so-called reality (the surrounding physical and social world) $i$.

A good example of this is the picture shown in Figure 5, which shows the well-known Kanizsa triangle, where no triangle exists, but we even see two! The first and most important one, the one that gives the name to the picture, is the upright triangle, which is usually seen as brighter than the page (it is physically not!') and seems to occlude three black discs and a second inverted triangle outlined in black. We say that the first one is the most important because it does not exist at all in the physical world, where there are only three black "Pacman" and three pairs of lines arranged as angles. Knowing how things are in the physical world does not change our perception of it because, as Kanizsa $(1955,1987)$ says, one thing is what we know (and think) about reality and another one is what we see (or perceive) about the world (Kanizsa and Gerbino, 1982). If the upright triangle were a road sign, our behaviour would be influenced by it despite its non-physical existence, unless we operate a transition from perception to cognition: knowing how things are in the physical world does not change our perception but can help us modulate our behaviour by suspending the coercive effect that perception has on us.

The part concerning the optical-geometric illusions may include a higher number of examples than the ones reported in this paper if this is required by the situation such as the 


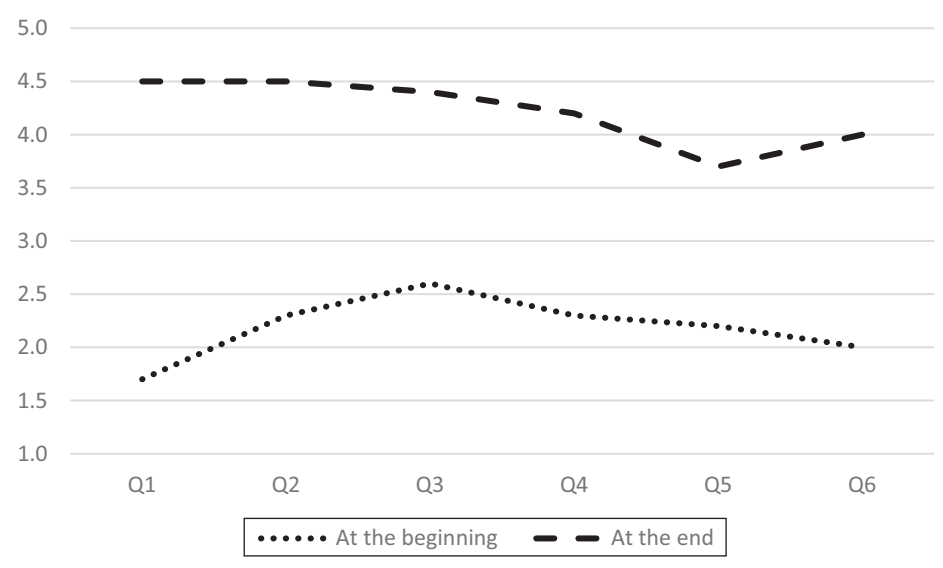

Note: Participants at the beginning (data refer to 63 participants) and at the end (data refer to 57 participants) of the course
Competences in young Italian apprentices

Figure 5.

Means of the answers to the 6 questions related to perception and administered to participants

one by Zöllner illustrated in Figure 6, where the oblique lines do not appear as parallel even if they are. In our experience, after the first three or four illusions, participants are eager to see more, which can be taken as an index of involvement and interest.

\section{Macro-phase 2: Advanced perception-based training}

Micro-phase 2.1: Ambiguous figures. Aims: This micro-phase aimed to begin to connect the reasoning on perception to our relational behaviours of communication and cooperation.

Stimuli: To avoid that the apprentices think that the "tricks in which we fall" are possible only with simple geometric images, the next step involves showing them the so-called ambiguous figures such as the one by Boring shown in Figure 7 (Figure 3). Indeed,

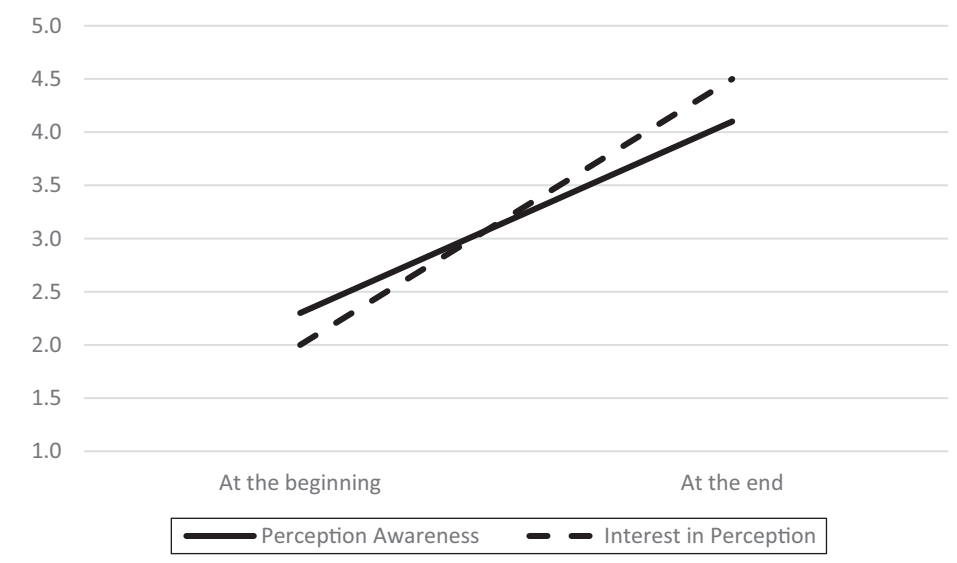

Note: At the beginning (data refer to 63 participants) and at the end of the course (data refer to 57 participants)

Figure 6.

Means obtained by participants in the two components of "perception awareness" and "interest in perception" 
EJTD

$45,6 / 7$

\section{8}

Figure 7.

Means of the answers to the six questions related to perception and administered to participants

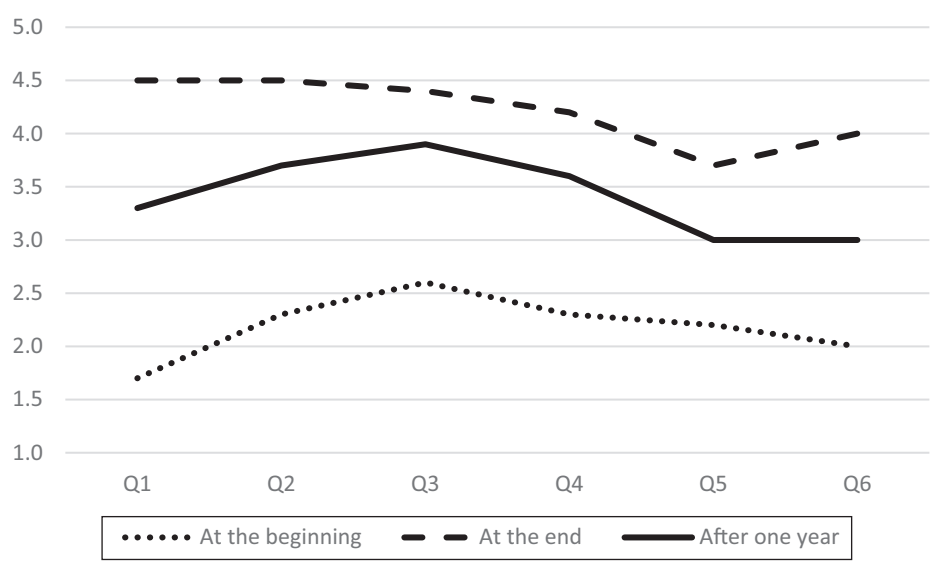

Note: At the end of the course (data refer to 57 participants) and after about one year from the end of the course (data refer to 46 participants)

ambiguous figures are more complex than the segments, lines and geometrical patterns previously seen and are experienced by people as "more natural".

The figure by Boring, that requires people to say what they see, whether the face of an old woman or the one of a young lady, allows not only to highlight the different perceptions inside the classroom - where there are some who see the old woman, others who see the young lady and others who see both - but also to stimulate the cooperation between participants so that they help each other to see one or the other of the two perceptual solutions not immediately perceived. In this way, the part involving the ambiguous figures serves to arise perceptual and attitude issues that have to do with our relational and social behaviours such as communication and cooperation.

An example usually helps participants to understand. Let us say that in front of the image shown in Figure 7 there are two people, one who only sees the old woman and the other one who only sees the young lady. Technically, they are both right, even if partially. How could we help them to cooperate so that each of them is able to see the other "truth"? The probability that these two people cooperate for a better and more complete understanding of the situation, rather than fighting over who sees well, and therefore is right, depends on three variables:

(1) Time: it takes time to cooperate and assume that attitude of openness towards the others and of interest for their points of view that favours a work "with" rather than "against" (time pressure is not a friend of cooperation); so, we should give people time.

(2) Ability: time is not enough. People need to be able to cooperate and stimulate one another on a collaborative level (for example through one of the numerous methods of asking questions such as: "interestingly, you say you see a young lady where I see an old woman; can you help me see what you see"? so, let us teach people to express their points of view for what they are (just points of view, not absolute truths) and to ask for help.

(3) Motivation: other than time and ability, motivation is needed. If the two people of the example are neither interested nor curious to know and understand the point of view of the other and do not want to abandon their personal position (their comfort zone), they are not likely to cooperate even if they have time and are able to do it. 
However, if the two people of the example have time or are given time (for example by the organizations they work in), possess the ability (perhaps because they were given appropriate training) and feel motivated (perhaps because they are encouraged by their organizations to be open to others' points of view), then it is possible that what George Bernard Shaw said can be achieved:

"If you have an apple and I have an apple and we exchange these apples then you and I will still each have one apple. However, if you have an idea and I have an idea, and we exchange these ideas, then each of us will have two ideas".

Cooperation is served.

Other examples of ambiguous figures that can attract attention and stimulate cooperation in the classroom are shown in Figures 8-10.

Micro-phase 2.2: Paintings and literary pieces. Aims: This micro-phase aimed to go further and push the reasoning produced so far so that participants start seeing the connection between the way our perception works and the way we behave from a relational and social point of view.

Stimuli: For general culture and to further stimulate the apprentices so that they are convinced that certain phenomena are not limited to black and white figures, created explicitly by psychologists, in this part of the perception-based intervention it is useful to make use of more complex images (Figure 4) such as the ones taken from painters Escher and Salvador Dali, of which Figures 11 and 12 are two examples, as also suggested by Kandel in his books (Kandel suggests that some paintings by Italian Renaissance painter Giuseppe Arcimboldo are used).

This part of the perception-based training intervention, with the use of paintings, also serves to link the considerations made up to now on the perceptual processes to the cognitive and emotional processes that can be connected to those. Indeed, in the state of "crisis" opened up by the optical-geometric illusions and the ambiguous figures previously presented, other than the paintings, it is possible to introduce some verses of poems chosen

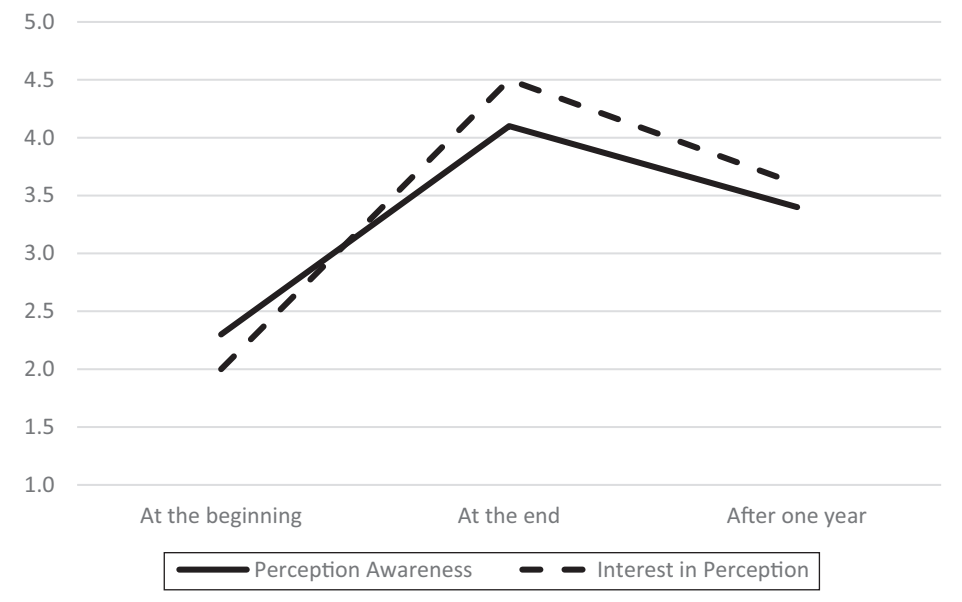

Note: At the beginning (data refer to 63 participants), at the end of the course (data refer to 57 participants) and after about one year from the end of the course (data refer to 46 participants)
Competences in young Italian apprentices

559

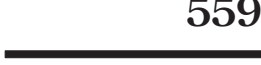


EJTD

$45,6 / 7$

ad hoc [5], some aphorisms or some short literary pieces (like the one taken from The Little Prince and related to his drawing of a snake eating an elephant, invariably interpreted by adults as a hat) that allows a transition to more exquisitely communicative, social and relational themes such as passive, assertive and aggressive communication styles, which is a training operation found in the book entitled The Little Prince Puts On His Tie (Vilaseca, 2017), one literary and no "scientific" example of a perception-based training intervention.

\section{0}

\section{Statistical analyses}

To test hypotheses and to statistically compare the four groups of participants both at the beginning and at the end of the course concerning the six questions about perception, the two components of "perception awareness" and "interest in perception" and the two questions about communication and cooperation, parametric (because $N>10$ ) and nonparametric (because $N<30$ ) methods of analysis of variance (repeated measures analysis of variance) were used. Besides, Pearson correlation coefficients were calculated between the two components and the two questions on communication and cooperation.

\section{Findings}

As no statistically significant differences between groups emerged $(\phi>0.05)$, the results are presented, keeping the answers of the participants of the four groups together.

The first hypothesis that at the end of the perception-based training intervention participants show increased interest in and awareness of their perceptual processes, is confirmed $(p<0.01)$. Figure 5 reports the means of the answers to the six questions at the beginning (data refer to 63 participants) and at the end of the course (data refer to 57 participants). At the end of the course, participants expressed their enthusiasm for the training received, also concerning the part on the psychology of perception. Figure 5 confirms this enthusiasm. First, all the answers to the six questions related to perception obtain higher scores at the end of the course. Second, the answer to the first question ("How interested are you in the topic of human perception"?) obtains the lowest score at the beginning of the course (1.7) and the highest at the end (4.5), testifying to the fact that the interest in the subject, very low at the beginning, has risen at the end.

Also Figure 6 that reports the means obtained by participants in the two components of "perception awareness" and "interest in perception" at the beginning and the end of the course confirms the first research hypothesis. The means of both the components increase from the beginning to the end.

After one year, 46 out of the 63 participants were recruited again because of another compulsory training course organized as part of their apprenticeship (not all the workers and employees were still apprentices after one year). Figure 3 is the same as Figure 5 with the addition of the means related to the answers to the six questions after about one year from the end of the course (continuous line). The same goes for Figure 8, which is like Figure 6, with the addition of follow-up data.

As for the two questions, one about communication (C1) and one about cooperation (C2), the trend of their means from the beginning, to the end and after one year is shown in Figure 9.

As $\mathrm{C} 1$ and $\mathrm{C} 2$ are questions asking participants to express their opinion about the possession of specific skills, it is not surprising that their levels of communication and cooperation at the beginning are positioned close to the middle. In fact, as for these competencies, people, in the absence of recognized skills, tend to put themselves in the middle, neither among the worst nor among the best (Burro et al., 2011).

After about one year, all the answers to the six questions related to perception and the means of the two components and the two questions of communication and cooperation, still 


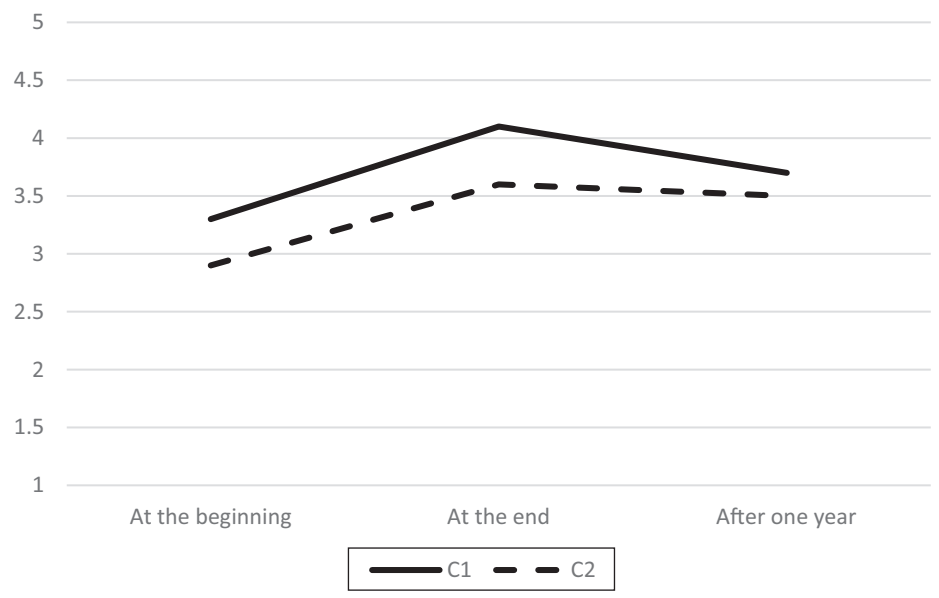

Notes: At the end of the course (data refer to 57 participants) and after about one year from the end of the course (data refer to 46 participants)

Competences in young Italian apprentices 561

Figure 9. Means obtained by participants in the two about communication (C1) and cooperation (C2)

score higher than at the beginning, despite the physiological decline, that is always observed when participants move away from the end of a psychosocial training intervention as the one here presented (cfr. for example, Martin, 2010). This can be read as an indication of the effectiveness of the training provided.

The second hypothesis that participants' increased interest in and awareness of perceptual processes are positively related to their relational competences in communication and cooperation was partially confirmed. Only "perception awareness" is significantly and positively correlated to the two questions of communication and cooperation, as shown in Table 3.

Other than the quantitative data suggesting that the perception-based training intervention was most effective, also the qualitative feedbacks from participants both during and at the end of the course go in the same direction. Surprise, wonder, disbelief and interest are just some of the emotions experienced and declared by participants in response to the optical-geometric illusions and the ambiguous figures shown to them. Alongside these emotions, participants often asked questions and tried reflections that revealed how and how much their certainty that things are perceived in a certain way because they are in that way was failing. Finally, the communicative styles of participants gradually changed as they realized that their maximum was to express their impressions, their perceptions and their points of view through incipits such as "I think" or "I feel" or, again, "it seems to me".

Components of C1. In your opinion, how well do you C2. In your opinion, how able are you to cooperate perception communicate with others? with others in life and at work?

Table 3.

\begin{tabular}{lll}
\hline Perception & $0.33^{* *}$ & $0.21^{*}$ \\
awareness & 0.11 & 0.09 \\
$\begin{array}{l}\text { Interest in } \\
\text { perception }\end{array}$ & &
\end{tabular}

Notes: $* p<0.05 ; * * p<0.01$

Correlations between the two components of perception and the two questions of communication and cooperation 
EJTD

$45,6 / 7$

Practically, participants became aware of the fact that the only sensible thing we can do from a relational point of view is to speak about ourselves and our perceptions, impressions, feelings and sensations and not about objects or events as if they surely are as they appear.

\section{Discussion}

"Beauty is in the eye of the beholder" is an old saying used to express the fact that not all people have the same opinions about what is attractive. Now that we have made this journey in the perception and in the mechanisms that make us behave in one way or another based on what we perceive, we can add further meaning to this saying: not only beauty is in the eye of the beholder but also the whole world around us, with its physical and social characteristics, is co-built by our eyes and our perception processes.

The way we perceive the world around us is influenced both by aspects related to bottom-up genetic processes, that have to do with the sensory pathways that activate brain processes and by top-down psychological processes, that have to do with what we have learnt and stored in memory following our sensorial, relational and social experiences. This means at least two things (Kandel, 2012, 2016):

(1) the way we perceive the world around us also depends on a process of construction of the world itself that starts from us and from the cognitive and emotional processes, conscious and unconscious, that take place inside us; and

(2) the way we perceive the world around us today also depends on processes based on past learning, and therefore, this means that we have learnt to perceive things as we perceive them.

Knowing all this and showing it to participants to such training courses such as the one reported in this paper help them develop a healthy relativism towards what we believe to be real, objective and absolute; and to assume that attitude exemplified by such communicative expressions as "I think", "I feel", "it seems to me" that help everyone express themselves better with others and to avoid that kind of dogmatism, that is often the basis of misunderstandings, conflicts and breakdowns. In other words, knowing how we work from the point of view of our perception processes help us communicate and interact better with others, less abruptly and drastically and in a softer and more involving way.

The apprentices involved in the perception-based training intervention reported in this paper were quite young, with a not so rarely negative scholastic experience and "forced" to attend a compulsory course that delivered, among others, a module on relational competences, that is to say, on their way of being with others in life and at work. It seemed to us at least risky, in these conditions, to deliver a typical training course on relational competences based on the managerial approach and starting immediately from the concepts of communication and communication styles, relations with others and verbal and nonverbal communication (topics covered after the first $8 \mathrm{~h}$ of the perception-based training intervention presented in this paper). Starting from perception and involving the apprentices in practical activities related to optical-geometric illusions, ambiguous figures and pieces of art seemed to us a better choice.

The choice proved to be successful, both for the involvement obtained in participants who started with a low level of motivation to participate and learn and for the results obtained in terms of change in their "perception awareness" and "interest in perception", other than communication and relational styles. Involving participants in the opticalgeometric illusions and ambiguous figures has meant offering them pieces of world and reality able to question their beliefs about why things are seen as they are seen and to 
change their attitudes towards the world, both physical and social, which, in the case of the apprentices of the perception-based training intervention here presented, worked better than frontal lectures or philosophical disquisitions.

\section{Limitations and future research}

As in all studies in which there is no control group (in this case a comparable group of apprentices who did not take any course or followed a different course), this study suffers from the fact that each conclusion is taken from internal observations without comparisons with external criteria. Also, participants are both low in number and geographically homogenous. Further research should apply this kind of perception-based intervention to wider groups of workers and employees coming from different parts of the world. Nevertheless, the fact that no statistically significant differences were found in the four groups to which the same type of training was delivered seems to go in the direction of concluding that the course has been effective in the same way for everyone. Further research is needed, though to test this effectiveness.

\section{Notes}

1. In this paper, we cite the most recent versions of even those books first published many years ago. This is to stress the modernity and the topicality of the concepts expressed in them.

2. In Skinner, $\mathrm{ABC}$ stands for antecedent, behaviour, consequence; In Ellis, $\mathrm{ABC}$ stands for activating event, beliefs, consequences (both emotional and behavioural).

3. Participants may say that Figure 1 represents a track, a road, a stream or a pipe [...] or even two rows of people facing each other, just to give a few examples of the kind of answers, which is possible to get when you ask people to say what they see in Figure 1 and the contribution they give, both cognitively and emotionally, to the perception and the construction of the world. Let participants feel free to produce their answers and take note of them.

4. Even in this case the answers given by participants are several.

5. An Italian example is the poem "Il sole nero" (The black sun) by Gianni Rodari, who tells the story of a child who has drawn a black sun and all the adults around her are worried that she is depressed or something, while the title of the drawing, which no one has read before and is only revealed at the end of the poem, is the eclipse.

\section{References}

Ammentorp, J., Sabroe, S., Kofoed, P.E. and Mainz, J. (2007), "The effect of training in communication skills on medical doctors' and nurses' self-efficacy: a randomized controlled trial", Patient Education and Counseling, Vol. 66 No. 3, pp. 270-277.

Berkhof, M., van Rijssen, H.J., Schellart, A.J.M., Anema, J.R. and van der Beek, A.J. (2011), "Effective training strategies for teaching communication skills to physicians: an overview of systematic reviews", Patient Education and Counseling, Vol. 84 No. 2, pp. 152-162.

Broadbent, D.E. (2013), Perception and Communication, Pergamon Press, Oxford.

Burro, R., Sartori, R. and Vidotto, G. (2011), "The method of constant stimuli with three rating categories and the use of Rasch models", Quality and Quantity, Vol. 45 No. 1, pp. 43-58.

Costantini, A., Ceschi, A., Viragos, A., De Paola, F. and Sartori, R. (2019), "The role of a new strengthbased intervention on organisation-based self-esteem and work engagement: a three-wave intervention study", Journal of Workplace Learning, Vol. 31 No. 3, pp. 194-206.

\section{Competences in young Italian apprentices}

563 
EJTD

$45,6 / 7$

Cunico, L., Sartori, R., Marognolli, O. and Meneghini, A.M. (2012), "Developing empathy in nursing students: a cohort longitudinal study", Journal of Clinical Nursing, Vol. 21 No. 13-14, pp. 2016-2025.

Ellis, A. (1994), Reason and Emotion in Psychotherapy, Stuart, New York, NY.

Fechner, G. (1966), Elements of Psychophysics, Holt, Rinehart and Winston, TX.

Grondin, S. (2016), Psychology of Perception, Springer International Publishing.

Kandel, E. (2012), The Age of Insight: The Quest to Understand the Unconscious in Art, Mind, and Brain, from Vienna 1900 to the Present, Random House, New York, NY.

Kandel, E. (2016), Reductionism in Art and Brain Science: Bridging the Two Cultures, Olumbia University Press, New York, NY.

Kanizsa, G. (1955), "Margini quasi-percettivi in campi con stimolazione omogenea", Rivista di Psicologia, Vol. 49, pp. 7-30, English translation, "Quasi-perceptual margins in homogenously stimulated fields", in Petry, S. and Meyer, G.E. (Eds) (1987), The Perception of Illusory Contours, pp. 40-49, Springer, New York, NY.

Kanizsa, G. and Gerbino, W. (1982), “Amodal completion: seeing or thinking?” in Beck, J. (Ed.), Organization and Representation in Perception, Lawrence Earlbaum, NJ, pp. 167-190.

Koffka, K. (2014), Principles of Gestalt Psychology, Mimemis, Milano.

Kanizsa, G. (1987), "Quasi-perceptual margins in homogeneously stimulated fields”, in Petry, S. and Meyer, G.E. (Eds) (1987), The Perception of Illusory Contours, Springer, New York, NY, pp. 40-49.

Kölher, W. (1970), Gestalt Psychology: The Definitive Statement of the Gestalt Theory, Liveright, New York, NY.

Marr, D. (2010), Vision: A Computational Investigation into the Human Representation and Processing of Visual Information, The MIT Press, Cambridge, MA.

Martin, H.J. (2010), "Improving training impact through effective follow-up: techniques and their application”, Journal of Management Development, Vol. 29 No. 6, pp. 520-534.

Meredith, J.R. and Mantel, S.J. (2011), "Project management”, A Managerial Approach, Wiley and Sons, New York, NY.

Mitterer, H., Horschig, J.M., Müsseler, J. and Majid, A. (2009), "The influence of memory on perception: it's not what things look like, it's what you call them", Journal of Experimental Psychology, Learning, Memory, and Cognition, Vol. 35 No. 6, pp. 1557-1562.

Nevis, E. (2013), "Organizational consulting”, A Gestalt Approach, Gestalt Press, New York, NY.

Salas, E., Bowers, C.A. and Edens, E. (2001), "Improving teamwork in organizations”, Applications of Resource Management Training, Taylor and Francis, London.

Sartori, R. and Pasini, M. (2007), "Quality and quantity in test validity: how can we be sure that psychological tests measure what they have to?", Quality and Quantity. International Journal of Methodology, Vol. 41, pp. 359-374.

Sartori, R. and Tacconi, G. (2017), "Carrying out studies on competence-based training for career development", European Journal of Training and Development, Vol. 41 No. 1, pp. 2-7.

Sartori, R., Ceschi, A. and Costantini, A. (2017), "The human side of open innovation: what room for training and development?", in Salampasis, D. and Mention, A.L. (Eds), Open Innovation: Bridging Theory and Practice: Volume 2:. Unveinling the Power of the Human Element, World Scientific, Singapore, pp. 111-133.

Sartori, R., Favretto, G. and Ceschi, A. (2013), "The relationships between innovation and human and psychological capital in organizations: a review”, The Innovation Journal, Vol. 18, pp. 1-18.

Sartori, R., Costantini, A., Ceschi, A. and Tommasi, F. (2018), "How do you manage change in organizations? Training, development, innovation, and their relationships", Frontiers in Psychology, Vol. 9, pp. 313.

Skinner, B.F. (1966), The Behavior of Organisms: An Experimental Analysis, Appleton-Century-Crofts, New York, NY. 
Tomietto, M., Paro, E., Sartori, R., Maricchio, R., Clarizia, L., De Lucia, P., Pedrinelli, G. and Finos, R. and PN Nursing Group (2019), "Work engagement and perceived work ability: an evidence-based model to enhance nurses' well-being”, Journal of Advanced Nursing, Vol. 75 No. 9, pp. 1933-1942.

Tucker, R. (2009), "The anticipatory regulation of performance: the physiological basis for pacing strategies and the development of a perception-based model for exercise performance", British Journal of Sports Medicine, Vol. 43 No. 6, pp. 392-400.

Vilaseca, B. (2017), The Little Prince Puts on His Tie, CreateSpace Independent Publishing Platform.

Wilson, D.A. and Stevenson, R.J. (2003), "The fundamental role of memory in olfactory perceotion",

Competences in young Italian apprentices Trends in Neurosciences, Vol. 26 No. 5, pp. 243-247.

\section{Further reading}

Sartori, R. and Perini, M. (2015), “Apprendistato e formazione psicosociale: un'esperienza di conduzione di moduli di socializzazione e competenze relazionali per apprendisti artigiani”, Rassegna CNOS, Vol. 31, pp. 91-110.

Wertheimer, M. (1982), Productive Thinking, University of Chicago Press, Chicago, IL.

\section{Corresponding author}

Riccardo Sartori can be contacted at: riccardo.sartori@univr.it

For instructions on how to order reprints of this article, please visit our website: 